\title{
SECADO POR ASPERSIÓN Y SU EFECTO SOBRE LA VIABILIDAD DE LOS MICROORGANISMOS PRESENTES EN SUERO FERMENTADO CON GRÁNULOS DE KEFIR.
}

\author{
A.M CHAUX ${ }^{1}$, L.M JIMENEZ ${ }^{2}$, K MOTATO $^{2}$, G. HERNANDEZ $^{3}$ \\ ${ }^{1}$ Universidade Estadual Paulista, Departamento de Engenharia de Alimentos \\ ${ }^{2}$ Universidad de Antioquia, Facultad de Química Farmacéutica \\ ${ }^{3}$ Universidad Nacional de Colombia-Sede Medellin, Facultad de Ciencias Agrarias.
}

\begin{abstract}
RESUMEN- Este trabajo de investigación evaluó el efecto de la maltodextrina y las condiciones de operación en el proceso de secado por aspersión de suero de leche fermentado con gránulos de kéfir, sobre la viabilidad de las bacterias ácido lácticas, mohos y levaduras presentes en este producto. Inicialmente se evaluaron las condiciones de fermentación del suero lácteo a diferentes concentraciones de inoculo de kéfir que posteriormente fue secado utilizando tres temperaturas para la entrada de aire $\left(200,190\right.$ y $\left.180{ }^{\circ} \mathrm{C}\right)$, en todas las pruebas se utilizó $20 \%$ de maltodextrina como vehículo protector. Los resultados indican que las tres temperaturas utilizadas en el proceso, reducen en un ciclo logarítmico la población de las bacterias ácido lácticas, mohos levaduras. No obstante su recuento en el producto en polvo alcanzó valores del orden de $10^{6} \mathrm{y}$ $10^{7}$ unidades formadoras de colonia por gramo, indicando la viabilidad de la metodología de secado por aspersión en la obtención de este tipo de microrganismos en polvo.
\end{abstract}

\section{INTRODUCCIÓN.}

El Kéfir es una leche fermentada que tuvo su origen en las montañas Caucásicas, el Tíbet o Mongolia hace muchos siglos; las personas caucásicas descubrieron que la leche transportada en bolsas de cuero podía fermentarse y se convertía en una bebida refrescante (IRIGOYEN et al 2005) . El cultivo iniciador para producir esta bebida, son gránulos de forma irregular, similares a la coliflor, gelatinosos de color blanco o amarillento y con un tamaño que puede variar entre 1 a $6 \mathrm{~mm}$. Estos gránulos de kéfir, tienen una variada y compleja composición microbiana que incluye especies de levaduras, bacterias ácido lácticas (LAB), bacteria ácido acéticas (AAB), bacterias propiónicas y hongos filamentosos (IRIGOYEN et al.2005, WITTHUHN et al. 2005). El Kéfir es producido por el amplio espectro de las especies microbianas que lo componen. Los 

levaduras componen la parte restante dentro del gránulo de kéfir (HSI-CHIA et al 2008).

Las bacterias contenidas en los gránulos de kéfir, producen una serie de compuestos antimicrobianos los cuales incluyen ácidos orgánicos de cadena corta como el ácido láctico, ácido acético, y ácido propiónico, antibióticos, dióxido de carbono, peróxido de hidrógeno, los cuales inhiben la proliferación y el deterioro ocasionado por otros microorganismos patógenos que pudieran entrar en el kéfir de leche. Por su parte, las levaduras son muy importantes en la fermentación del kéfir porque producen etanol y dióxido de carbono, los cuales le dan frescura y esponjosidad característica a las leches fermentadas. ${ }^{4}$. Los productos finales más importantes de la fermentación son ácido láctico, acetaldehído y diacetil (IRIGOYEN et al. 2005, TELLO ROBLES, 2013, GUK ZEL-SEYDIM et al. 2000). Además durante la fermentación aumentan las vitaminas B1, B12, calcio, amino ácidos, ácido fólico y vitamina K (IRIGOYEN et al. 2005, GUK ZEL-SEYDIM et al. 2000)

El lactosuero es uno de los materiales más contaminantes que existe en la industria alimentaria, debido a que cada 1000L de lactosuero genera $35 \mathrm{~kg}$ de demanda biológica de oxígeno (DBO) y cerca de $68 \mathrm{~kg}$ de demanda química de oxígeno (DQO) (INDA, 2000). A nivel mundial, aproximadamente el $47 \%$ de los 115 millones de toneladas de suero producidos anualmente en el mundo, se desechan en ríos, lagos y otros centros de aguas residuales, o en el suelo, lo que representa una pérdida significativa de recursos y contaminación ambiental (PARRA HUERTAS, 2009). En Colombia, según la Federación de Ganaderos (Fedegan), la producción de leche en Colombia, para el año 2012 fue de 5884 millones de litros (PÉREZ \& ORTEGA, 2012), de los cuales, aproximadamente un 18\% (1.059 millones de litros) se destinó a la producción de quesos, lo que quiere decir que la producción nacional de lactosuero, correspondió a 953.09 millones de litros (PARRA HUERTAS, 2009); y en el Valle de Aburrá y el Oriente Antioqueño hay alrededor de 28 empresas lácteas, que tienen entre sus líneas de producción la elaboración de queso fresco y quesito, lo que representa una generación de 1739793L por ano de lactosuero (LONDOÑO, 2006)

Los principales componentes del lactosuero son la lactosa (44-58 g/L), las proteínas $(3,0-4,0 \mathrm{~g} / \mathrm{L})$ y las sales minerales $(4,3-9,5 \mathrm{~g} / \mathrm{L})$; aunque el lactosuero tiene un contenido proteico bajo, sus proteínas son de alto valor biológico (por su contenido de triptófano, lisina y aminoácidos azufrados); además el suero presenta una cantidad rica en minerales donde sobresale el potasio, seguido del calcio, fósforo, sodio y magnesio. Cuenta también con vitaminas del grupo B (LONDOÑO, 2006, LONDOÑO et al. 2008)

Considerables esfuerzos han sido realizados en el pasado para explorar nuevas alternativas para la utilización de lactosuero y reducción de la contaminación ambiental. Se han obtenido productos como las bebidas refrescantes, bebidas fermentadas, y alcohólicas, proteína unicelular, biopelículas, producción de ácidos orgánicos, concentrados de proteínas, derivados de lactosa entre otros (LONDOÑO, 2006).

\section{Secado para microorganismos probióticos}

La preservación de microorganismos por diferentes metodologías de secado, se han utilizado durante décadas, uno de los métodos que se destacan es el secado por aspersión, más conocido como spray dry. En él, un líquido se atomiza en una corriente de aire caliente para 

partículas secas de sólido que se separan de la corriente de aire GEANKOPLIS, 1998,

El secado por aspersión, es uno de los procesos más prometedores para la producción de probióticos secos, debido a su alta tasa de funcionamiento, bajo costo de operación y mantenimiento, además del alto grado de supervivencia de los microorganismos (PAPAPOSTOLOU et al. 2008) por tanto es una alternativa para la preservación y la concentración de la microorganismos (SUNNY-ROBERTS, 2008). Obtener probióticos secos por aspersión con un número elevado de bacterias viables es deseable porque permite tener un buen almacenamiento, transporte y finalmente utilizarlo para el desarrollo de alimentos funcionales. GILLIAN et al. 2002, WEN-CHIAN et al.2001, ANANTA et al. 2004' LUNA-SOLANO et al 2004)

El presente proyecto quiere evaluar el efecto de secado por spray dry sobre la viabilidad de los microorganismos presentes en suero lácteo fermentado con gránulos de kéfir, a fin de dar valor agregado a un residuo agroalimentario para su potencial uso dentro de la industria alimentaria como cultivo iniciador con características probióticas o aditivo en diversos alimentos.

\section{MATERIALES Y MÉTODOS}

Los pasos a seguir son los siguientes:

Activación y producción de los gránulos de kéfir: la leche entera se inocula con $7 \%$ de gránulos de kéfir, y se deja incubando a $25^{\circ} \mathrm{C}$ por 24 horas. Después de la incubación a estas condiciones, se separa los gránulos de kefir de la leche fermentada, se lavan con agua desionizada y se repite este proceso por un período de 30 días, a fin de obtener la cantidad necesaria de gránulos de kefir.

Preparación de inóculo madre inicial con suero lácteo: Un inóculo inicial fue preparado empleando los gránulos de kéfir previamente activados y usando el suero lácteo pasterizado. Para ello se inocula el suero lácteo con $5 \%$ de gránulos de kefir y se deja incubando a una temperatura de $25^{\circ} \mathrm{C}$ realizando cada hora medición de $\mathrm{pH}$. Estas mediciones se toman hasta lograr un pH óptimo de fermentación (4.6). Durante este tiempo de fermentación se garantiza que se obtiene la cantidad de microorganismos necesarios y viables para que este inóculo inicial sirva como cultivo starter para fermentar una cantidad superior de suero.

Fermentación: Dentro de esta etapa, se evaluó si la agitación influye sobre el crecimiento de los microorganismos del kéfir en el suero lácteo. Para ello, se inoculó el suero lácteo con 10 e $20 \%$ de inoculo madre inicial en erlenmeyers de vidrio con $250 \mathrm{ml}$ de suero y una temperatura de $25^{\circ} \mathrm{C} .3$ elenmeyer se agitaron en un agitador orbital marca GUFA Instruments a $100 \mathrm{rpm}$ y los otros 3 sin agitación. Se dejan fermentando y cada hora se realizan mediciones de $\mathrm{pH}$ con un ph-metro marca HANNA Instruments y se determina la acidez titulable con $\mathrm{NaOH} 0.1 \mathrm{~N}$ y se expresa como porcentaje de ácido láctico. Las fermentaciones con y sin agitación se dan terminadas a las 24 horas de iniciado el proceso. Una vez definida la influencia de la agitación en la fermentación del suero, se procedió a aumentar el volumen de éste a $1200 \mathrm{ml}$.

Recuento microbiano: El recuento en placa de las bacterias viables, tanto BAL como de mohos y levaduras, se realizaron utilizando los medios: Man Rogossa y Sharped (MRS) y Agar- 

incubaron durante 48 horas a $35^{\circ} \mathrm{C}$ en cámaras de anaerobiosis y los mohos y levaduras se incubaron a temperatura ambiente durante 48 horas.

Secado: se realiza en un secador por aspersión marca VIBRASEC, de una capacidad de 10L. Se utiliza maltodextrina de marca Bellchem disuelta con el suero fermentado, como vehículo protector, en una cantidad de $20 \%$. En el secado, la temperatura de salida del aire varía entre 80$82{ }^{\circ} \mathrm{C}$ y se varían 3 temperaturas de entrada del aire: 200,190 y $180{ }^{\circ} \mathrm{C}$; para experimento se usa $1200 \mathrm{ml}$ de suero fermentado, la velocidad de rotación del aspersor es de $20000 \mathrm{rpm}$.

Contenido de humedad: se realizan pruebas de contenido de humedad a cada una de las muestras secadas a diferentes temperaturas en una balanza para medición de humedad marca "OHAUS".

\section{RESULTADOS Y DISCUSIÓN}

Tabla 1. Datos de pH e acidez expresada \% de ácido láctico obtenidos de la fermentación con agitación y sin agitación.

\begin{tabular}{l|ccccc|ccccccc}
\hline \multicolumn{10}{c}{ Tiempo (horas) } \\
\hline & \multicolumn{10}{c|}{$\mathbf{p H}$} & \multicolumn{7}{c}{$\begin{array}{c}\text { Acidez titulable } \\
\text { (Expresada como Ácido Láctico) }\end{array}$} \\
\hline Tratamiento & 1 & 2 & 3 & 4 & 5 & 6 & 1 & 2 & 3 & 4 & 5 & 6 \\
Sin agitación & 5.35 & 5.33 & 5.31 & 5.27 & 5.23 & 4.82 & 0.227 & 0.252 & 0.277 & 0.289 & 0.302 & 0.331 \\
Con agitación & 5.36 & 5.33 & 5.3 & 5.25 & 5.2 & 4.5 & 0.228 & 0.25 & 0.279 & 0.291 & 0.308 & 0.452 \\
\hline
\end{tabular}

Tabla 2. Datos de recuento de bacterias lácticas de mohos y levaduras después de 24 horas de fermentación con y sin agitación.

\section{Tratamiento}

\begin{tabular}{lcc}
\hline & Sin agitación & $\begin{array}{c}\text { Con } \\
\text { agitación }\end{array}$ \\
\hline $\begin{array}{l}\text { Recuento de bacterias ácido lácticas } \\
\text { (UFC/ml) }\end{array}$ & $3.4 * 10^{8}$ & $4.5^{*} 10^{8}$ \\
$\begin{array}{l}\text { Recuento de bacterias ácido lácticas } \\
\text { (UFC/ml) }\end{array}$ & $3.4^{*} 10^{8}$ & $5.3^{*} 10^{8}$ \\
\hline
\end{tabular}


De la tablaXXCongressphrasileirg de que la fermentación con agitación mejora la eficiencia del proceso en términos del recuento de las bacterias ácido lácticas y de mohos y levaduras, lo cual puede ser corroborado con el descenso del pH hasta 4.5 después de 24 horas de fermentación, es por esta razón se establecieron estas condiciones como las adecuadas para fermentar el suero lácteo para su posterior secado.

Tabla 3. Efecto de la temperatura sobre el recuento de bacterias ácido lácticas y mohos y levaduras.

\begin{tabular}{ccccc}
\hline & $\begin{array}{c}\text { Antes del } \\
\text { secado }\end{array}$ & \multicolumn{2}{c}{$\begin{array}{c}\text { Temperatura entrada de aire al } \\
\text { secador }\left({ }^{\circ} \mathbf{C}\right)\end{array}$} \\
\hline $\begin{array}{c}\text { Recuento Microbiano } \\
\text { (UFC/ml) }\end{array}$ & & 200 & 190 & 180 \\
\hline Bacterias Ácido lácticas & $3.50^{*} 10^{8}$ & $1.1^{*} 10^{7}$ & $5 * 10^{7}$ & $6 * 10^{7}$ \\
\hline Mohos y levaduras & $6.40^{*} 10^{7}$ & 0 & $5.8^{*} 10^{7}$ & $7.5^{*} 10^{6}$ \\
\hline
\end{tabular}

De los resultados obtenidos después del proceso de secado por aspersión se pode decir que este tratamiento afecta tanto a las bacterias ácido lácticas como a los mohos y las levaduras ya que después del secado se observa una reducción de aproximadamente un ciclo logaritmo en su población con respeto al recuento inicial, sin embargo en términos de procesamiento el secado por aspersión permite la conservación de los microorganismo ya que las concentraciones finales están en la orden de $10^{6}$ a $10^{7}$, esto puede deberse al hecho de que el tiempo de secado de las gotas generadas por el aspersor es muy corto lo que evita una prolongada exposición del producto a las temperaturas de la entrada del aire, por la adición del vehículo protector o por la combinación de estas dos condiciones. Es importante resaltar que las bacterias ácido lácticas fueron menos termolábiles que los mohos y levaduras, como puede constatarse en la tabla 3 los mohos y las levaduras no resistieron el procesamiento a una temperatura superior a $190^{\circ} \mathrm{C}$, por esta razón se recomienda que el procesamiento sea llevado a cabo a temperaturas de entrada de aire menores a $190^{\circ} \mathrm{C}$.

\section{CONCLUSIÓN.}

Se concluye que el proceso de secado por aspersión para este tipo de microorganismos es viable, no obstante es muy importante estandarizar las condiciones de fermentación en un biorreactor para así garantizar que la población inicial de microorganismos sea del orden de $10^{10}$, para que después del secado se tenga microorganismos del orden $10^{9}$ o $10^{8}$ para poder así definirlo como un producto probiótico. 
ANANTA E., VOLKERT M., KNORR D. Cellular injuries and storage stability of spray-dried Lactobacillus rhamnosus GG. International Dairy Journal 2004; 15 (2005) 399-409.

BARBOSA-CÁNOVAS G, JULIANO E, YAN H. FOOD POWDERS Physical Properties, Processing and Funtionality. New York: Kluver Academic/Plenum Publishers; 2005.

GEANKOPLIS C. Procesos de transporte y operaciones unitarias.3 ed. México: Editorial Continental; 1998.

GILLIAN E. GARDINER P, EILIS O, JIM Kelly, J. Kevin Collinsb,Gerald Fitzgerald, R. Paul Ross, Catherine Stanton. A spray-dried culture for probiotic Cheddar cheese manufacture. International Dairy Journal 2002; 12 (2002) 749-756.

GUK ZEL-SEYDIM Z. B, SEYDIM A. C., GREENE A. K, BODINE A. B. Determination of Organic Acids and Volatile Flavor Substances in Kefir during Fermentation. Journal of food composition and analysis 1999; 13 (2000); 35-43.

HSI-CHIA C, SHENG-YAO W, MING-JU C. Microbiological study of lactic acid bacteria in kefir grains by culture-dependent and culture-independent methods. Food Microbiology; 25 (2008) 492-501.

INDA A. Optimización del rendimiento y aseguramiento de Inocuidad en la Industria de quesería. México: Organización de los Estados Americanos (OEA); 2000.

IRIGOYEN. A, ARANA. I, CASTIELLA. M, TORRE. P, IBÁÑEZ. F.C. Microbiological, physicochemical, and sensory characteristics of kefir during storage. Food Chemistry 2004; 90 (2005); 613-620.

LONDOÑO M, Sepúlveda J, Hernández A, Parra J. Bebida fermentada de suero de queso fresco inoculada con Lactobacillus casei. Rev.Fac.Nal.Agr.Medellín 2008; 61(1): 4409-4421.

LONDOÑO M. Aprovechamiento del suero ácido de queso doble crema para la elaboración de quesillo utilizando tres métodos de complementación de acidez con tres ácidos orgánicos. Perspectivas en nutrición humana 2006; (16): 11-20.

LUNA-SOLANO G, SALGADO-CERVANTES M.A, RODRÍGUEZ-JIMÉNEZ G.C, GARCÍAALVARADO M.A. Optimization of brewer's yeast spray drying process. Journal of ORTEGARIVAS Food Engineering 2004; 68 (2005) 9-18.

PAPAPOSTOLOU H, LOULOUDA A. Bosnea, ATHANASIOS A. KOUTINAS, M. Fermentation efficiency of thermally dried kefir. Bioresource Technology 2008; 99 (2008): 69496956. 
PARRA HUERTAS R. A. Lactosuero: importancia en la industria de alimentos. Rev.Fac.Nal.Agr.Medellín 2009; 62(1): 4967-4982.

PÉREZ R, ORTEGA R. Consejo Nacional de Calidad de la leche y prevención de la mastitis CNLM. [Sitio en internet]: Disponible em: http://lactividad.org/wp-content/uploads/2013/04/3.CONSEJO-NAL-CALIDAD-DE-LA-LECHE-Presentacion-COLOMBIA-IFCN-CNLM2012.pdf. Consultado: 13 de marzo de 2013.

SUNNY-ROBERTS E.O., KNORR D. The protective effect of monosodium glutamate on survival of Lactobacillus rhamnosus GG and lactobacillus rhamnosus E-97800 (E800) strains during spray-drying and storage in trehalose-containing powders. International Dairy Journal 2008; 19(2009): 209-214.

WEN-CHIAN L, HUNG-CHI H, CHENG-CHUN C. Survival of bifidobacteria after spraydrying. International Journal of Food Microbiology 2001; 74 (2002) 79-86.

WITTHUHN. R.C, SCHOEMAN. T, BRITZ T.J. Characterisation of the microbial population at different stages of Kefir production and Kefir grain mass cultivation. International Dairy Journal 2004; 15 (2005); 383-389. 